\title{
Defect chemistry and oxygen ion migration in the apatite-type materials $\mathrm{La}_{9.33} \mathrm{Si}_{6} \mathrm{O}_{26}$ and $\mathrm{La}_{8} \mathrm{Sr}_{2} \mathrm{Si}_{6} \mathrm{O}_{26}$
}

E-mail: m.islam@surrey.ac.uk; Fax: +44-1483-686851; Tel: +44-1483-686844

Received 10th March 2003, Accepted 19th May 2003

First published as an Advance Article on the web 6th June 2003

Computer modelling techniques have been used to examine the mechanistic features of oxygen ion transport in the $\mathrm{La}_{8} \mathrm{Sr}_{2} \mathrm{Si}_{6} \mathrm{O}_{26}$ and $\mathrm{La}_{9.33} \mathrm{Si}_{6} \mathrm{O}_{26}$ apatite-oxides at the atomic level. The potential model reproduces the observed complex structures of both phases, which are comprised of $\left[\mathrm{SiO}_{4}\right]$ tetrahedral units and $\mathrm{La} / \mathrm{O}$ channels. Defect simulations have examined the lowest energy interstitial and vacancy sites. The results suggest that oxygen ion migration in $\mathrm{La}_{8} \mathrm{Sr}_{2} \mathrm{Si}_{6} \mathrm{O}_{26}$ is via a vacancy mechanism with a direct linear path between O5 sites. Interstitial oxygen migration is predicted for $\mathrm{La}_{9.33} \mathrm{Si}_{6} \mathrm{O}_{26}$ via a non-linear (sinusoidal-like) pathway through the $\mathrm{La} 3 / \mathrm{O} 5$ channel. The simulations demonstrate the importance of local relaxation of $\left[\mathrm{SiO}_{4}\right]$ tetrahedra to assist in the facile conduction of oxygen interstitial ions. In general, the modelling study confirms that the high ionic conductivity in silicate-based apatites (with oxygen excess or cation vacancies) is mediated by oxygen interstitial migration.

\section{Introduction}

The development of new oxygen ion conductors is of considerable interest for potential electrochemical applications, especially solid oxide fuel cells and oxygen generators. Rare earth apatite materials have recently been attracting considerable interest in this regard following the report of silicate and germanate systems exhibiting conductivities higher than the conventional yttria-stabilised zirconia (YSZ) electrolyte at moderate temperatures. ${ }^{1}$

Apatite-type oxides take the general formula $\mathrm{M}_{10}\left(\mathrm{XO}_{4}\right)_{6} \mathrm{O}_{2 \pm y}$, where $\mathrm{M}$ is a metal such as a rare earth or alkaline earth and $\mathrm{X}$ is a p-block element such as $\mathrm{P}, \mathrm{As}, \mathrm{Si}$ or Ge. To date, a number of stoichiometries including anion/cation-deficient and anionexcess compositions have been investigated as ionic conductors, and results have shown that the cation-deficient and anion-excess materials exhibit far higher conductivity than the stoichiometric compositions. ${ }^{1-6}$ The highest conductivities are found for the oxygen-excess lanthanum based silicates and germanates, $\mathrm{La}_{10} \mathrm{Si}_{6} \mathrm{O}_{27}, \mathrm{La}_{10} \mathrm{Ge}_{6} \mathrm{O}_{27}$ and their $\mathrm{Sr}$ doped derivatives. These show conductivities comparable to, or better than, YSZ at $600{ }^{\circ} \mathrm{C} ., 7,8$ There is, however, some doubt regarding the phase purity of the high oxygen excess samples. High quality samples of lower oxygen content can be made, and whilst they show lower overall conductivity, they are still very promising. ${ }^{3,4,8,9}$ It has also been reported ${ }^{1,7}$ that conduction in these materials is wholly ionic, with high oxygen transference numbers $(>0.9)$ across a wide range of oxygen partial pressures.

In recent conductivity and neutron diffraction studies, Sansom et $\mathrm{al}^{3}$ reported that the non-stoichiometric $\mathrm{La}_{9.33^{-}}$ $\mathrm{Si}_{6} \mathrm{O}_{26}$ phase shows considerably higher conductivity and lower activation energy than the stoichiometric $\mathrm{La}_{8} \mathrm{Sr}_{2} \mathrm{Si}_{6} \mathrm{O}_{26}$ phase. It was proposed that this was correlated with a considerable degree of interstitial disorder in the $\mathrm{La}_{9.33} \mathrm{Si}_{6} \mathrm{O}_{26}$ sample, in which oxygen from the channel $\mathrm{O} 5$ site was displaced to a nearby "O6" position. It was also suggested that this might be related to local distortions of the structure caused by the non-stoichiometry at the La1/La2 positions (Fig. 1). Further work $^{4-6,9-11}$ investigating this effect has shown that cation nonstoichiometry and partial occupancy on these sites can have as great an affect on conductivity as the incorporation of excess oxygen into the system. Of additional interest are the studies ${ }^{5,6}$ in which $\mathrm{Ga}^{3+}$ and $\mathrm{Al}^{3+}$ are substituted onto the $\mathrm{Si}$ site. By doping in this way, the defect concentration is controlled whilst maintaining constant oxygen stoichiometry. For both systems it was found that conductivity could be dramatically improved by changing the degree of cation deficiency.

However, the precise defect properties and ion migration mechanisms in these complex systems at the microscopic level are still not clear, and are crucial to a greater understanding of their macroscopic transport behaviour. Atomistic modelling techniques are well suited to the investigation of such properties and have been applied successfully to oxygen transport studies of $\mathrm{LaMO}_{3}$ perovskite materials (where $\mathrm{M}=\mathrm{Mn}, \mathrm{Co}$, Ga). ${ }^{12-14}$ Electronic structure techniques have been used recently to study the fluorapatite structure. ${ }^{15}$ However, there is little previous work regarding the modelling of ion mobility in these apatite oxygen ion conductors to link up with the experimental data. Here we present the results of our atomistic

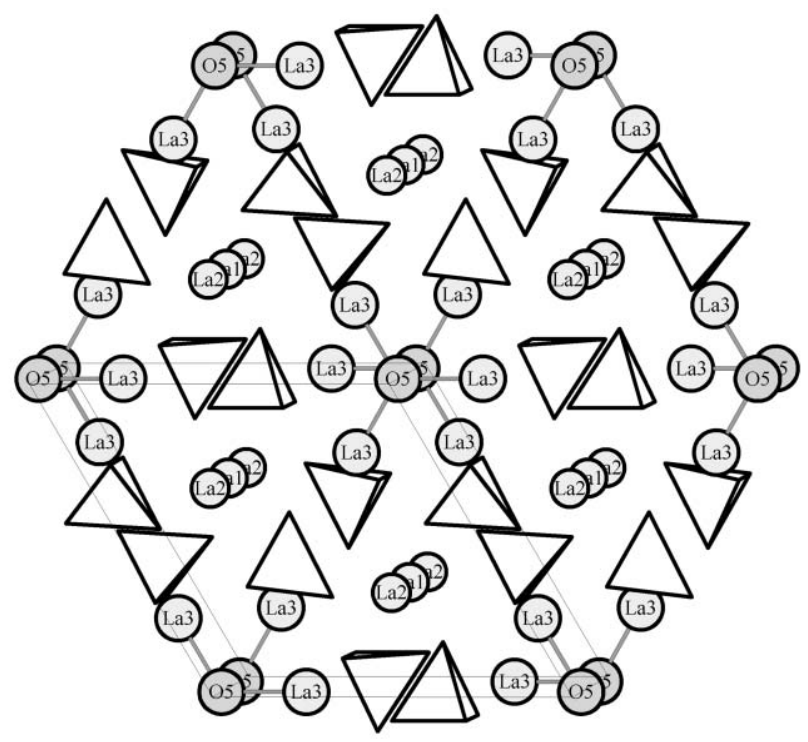

Fig. 1 The structure of $\mathrm{La}_{9.33} \mathrm{Si}_{6} \mathrm{O}_{26}$ apatite, showing $\left[\mathrm{SiO}_{4}\right]$ tetrahedra and La3/O5 and La1/2 "channels". 
studies on the intrinsic defect chemistry and oxygen ion migration mechanisms in the $\mathrm{La}_{9.33} \mathrm{Si}_{6} \mathrm{O}_{26}$ and $\mathrm{La}_{8} \mathrm{Sr}_{2} \mathrm{Si}_{6} \mathrm{O}_{26}$ materials.

\section{Simulation methods}

In this study, atomistic modelling techniques embodied in the GULP code ${ }^{16}$ were used to model our materials. These wellestablished techniques are comprehensively reviewed elsewhere, ${ }^{17,18}$ so only a brief description will be given here.

The calculations are based upon the Born model for polar solids. Each ion is assigned an integral charge corresponding to its formal oxidation state, with the interactions between ions represented in terms of a long-range Coulombic term plus an analytical function representing short-range repulsive and van der Waals interactions. In this work, these short-range interactions were modelled using the Buckingham potential:

$$
V_{i j}\left(r_{i j}\right)=A \exp \left(-r_{i j} / \rho\right)-C / r_{i j}{ }^{6}
$$

where $r$ is the interatomic separation and $A, \rho$ and $C$ are empirically derived parameters.

An additional three-body term was also used in this work. This is common in the modelling of silicate (and aluminosilicate) materials, ${ }^{18}$ and is necessary to take account of the angle-dependent nature of the $\mathrm{SiO}_{4}$ tetrahedral units. It is defined for each $\mathrm{O}-\mathrm{Si}-\mathrm{O}$ bond and takes the form of a harmonic angular constraint about the central Si:

$$
V_{3 \text {-body }}=1 / 2 k\left(\theta-\theta_{\mathrm{o}}\right)^{2}
$$

where $k$ is the bond force constant and $\theta_{\mathrm{o}}$ is the equilibrium bond angle. Such potential models have been used successfully to investigate molecular diffusion in zeolites ${ }^{18}$ and cation migration in aluminosilicate minerals. ${ }^{19}$

Because charged defects will polarise nearby ions in the lattice, accurate calculation of defect energies requires the inclusion of ionic polarisability in the model, particularly when modelling "soft" ions such as $\mathrm{O}^{2-}$. This is incorporated via the shell model of Dick and Overhauser, ${ }^{20}$ which provides a simple, yet effective, description of polarisability by treating each ion in terms of a massless shell connected to the ion core via a harmonic spring.

For the modelling of point defects, the Mott-Littleton approach was used, in which a defect is introduced into the energy-minimised lattice, and the surrounding ions partitioned into two regions. ${ }^{17} \mathrm{An}$ inner sphere of ions immediately surrounding the point defect (region 1) are then relaxed explicitly whilst the crystal bulk (region 2) is treated by computationally less expensive quasi-continuum methods.

\section{Results and discussion}

\subsection{Structural modelling}

As noted, apatite oxides take the general formula $\mathrm{M}_{10}\left(\mathrm{XO}_{4}\right)_{6} \mathrm{O}_{2 \pm y}$, where $\mathrm{M}$ is a metal such as $\mathrm{Ca}, \mathrm{La}$, or $\mathrm{Sr}$ and $\mathrm{X}$ is a p-block element such as $\mathrm{Si}$ or Ge. A depiction of the structure is shown in Fig. 1, from which it can be seen that the structure is not of the 3D framework type, but consists of isolated $\mathrm{XO}_{4}$ tetrahedra with channels running along the $c$-direction. The structure is hexagonal in symmetry, with the $\mathrm{X}$ cations taking tetrahedral coordination with the structural oxygen, whilst the $\mathrm{M}$ cations occupy two cavity sites (sevenand nine-coordinate). The nine-coordinate position lies in the centre of the smaller of the two structural channels, and depending upon the choice of space group is either a single four-fold position $\left(\mathrm{PG}_{3} / \mathrm{m}\right)$, or a pair of two-fold positions $\left(\mathrm{PG}_{3}\right.$, $P \overline{3})$ if cation ordering is present. The seven-coordinate positions lie around the periphery of the larger channel in the centre of which reside oxygen ions. For our simulation work, the neutron diffraction results of Sansom et al. ${ }^{3}$ were used as a reference, and hence the structure was described in terms of the $P \overline{3}$ space group.

As there is very little literature relating to the modelling of apatite materials, our initial approach to modelling the $\mathrm{La}_{8} \mathrm{Sr}_{2} \mathrm{Si}_{6} \mathrm{O}_{26}$ and $\mathrm{La}_{9.33} \mathrm{Si}_{6} \mathrm{O}_{26}$ structures was to apply a broad selection of published potentials. ${ }^{12,21-25} \mathrm{We}$ concentrated initially on reproducing the $\mathrm{SiO}_{4}$ tetrahedral units, and found that best reproduction was achieved using the $\mathrm{Si}^{4+}-\mathrm{O}^{2-}$ and $\mathrm{O}^{2-}-\mathrm{O}^{2-}$ pair-potentials, and $\mathrm{O}-\mathrm{Si}-\mathrm{O}$ three-body terms from work on zeolites ${ }^{21}$ and berlinite. ${ }^{22}$

Our preliminary simulation of the complex structures revealed significant differences between the calculated and experimental bond distances, particularly around the "border" region between the $\left[\mathrm{SiO}_{4}\right]$ tetrahedra and $\mathrm{La} / \mathrm{O}$ channels. Indeed these complex apatites may be viewed as "hybrid" structures comprised of covalent-like $\left[\mathrm{SiO}_{4}\right]$ units and ionic-like $\mathrm{La} / \mathrm{O}$ channels, which are not trivial to simulate.

For further refinement of the model we empirically derived new potential parameters for the $\mathrm{La}^{3+}-\mathrm{O}^{2-}$ short-range interaction for both compositions simultaneously. The shell model parameters for $\mathrm{La}^{3+}$ were transferred directly from successful modelling studies of a wide range of $\mathrm{LaMO}_{3}$ perovskites. ${ }^{13,14}$ Here the shell model was found to be useful in the simulation of ion transport in La-based oxides. In addition, the structural complexity of the lanthanum apatites includes cation non-stoichiometry (La vacancies) in certain compositions such as $\mathrm{La}_{9.33} \mathrm{Si}_{6} \mathrm{O}_{26}$.

Our final interatomic potentials are presented in Table 1 and details of our structural simulation are given in Table 2. It can be seen that our calculated unit cell edges and volumes deviate by approx. 1\% from experimental values and all bond lengths are reproduced to within 5\%. In particular, we have reproduced the "radii" of the O5 channel structure very well (given by the La3-O5 distances). In general, there is good agreement between experimental and simulated structures for both complex apatite systems, thus supporting the validity of the potentials used for the subsequent defect calculations.

Table 1 Interatomic potentials for $\mathrm{La}_{8} \mathrm{Sr}_{2} \mathrm{Si}_{6} \mathrm{O}_{26}$ and $\mathrm{La}_{9.33} \mathrm{Si}_{6} \mathrm{O}_{26}$

(a) Short range (potential cut-off $=12 \AA$ )

\begin{tabular}{lrcc}
\hline Interaction & \multicolumn{1}{c}{$A / \mathrm{eV}$} & $\rho / \AA$ & $C / \mathrm{eV} \AA^{-6}$ \\
\hline $\mathrm{Sr}^{2+}-\mathrm{O}^{2-}$ & 959.10 & 0.37210 & 0 \\
$\mathrm{La}^{3+}-\mathrm{O}^{2-}$ & 4579.23 & 0.30437 & 0 \\
$\mathrm{Si}^{4+}-\mathrm{O}^{2-}$ & 1283.91 & 0.32052 & 10.66 \\
$\mathrm{O}^{2-}-\mathrm{O}^{2-}$ & 22764.30 & 0.14900 & 27.89 \\
\hline
\end{tabular}

(b) Shell model

\begin{tabular}{lrr}
\hline Ion & \multicolumn{1}{c}{$Y / \mathrm{e}$} & \multicolumn{1}{c}{$k / \mathrm{eV} \AA^{-2}$} \\
\hline $\mathrm{Sr}^{2+}$ & 3.251 & 71.70 \\
$\mathrm{La}^{3+}$ & -0.250 & 145.00 \\
$\mathrm{O}^{2-}$ & -2.860 & 74.92 \\
\hline
\end{tabular}

\begin{tabular}{|c|c|c|c|}
\hline \multirow{2}{*}{ Bond } & \multicolumn{2}{|l|}{ Angle/ ${ }^{\circ a}$} & \multirow[b]{2}{*}{$k / \mathrm{eV} \mathrm{rad}^{-2}$} \\
\hline & $\mathrm{La}_{8} \mathrm{Sr}_{2} \mathrm{Si}_{6} \mathrm{O}_{26}$ & $\mathrm{La}_{9.33} \mathrm{Si}_{6} \mathrm{O}_{26}$ & \\
\hline $\mathrm{O} 1-\mathrm{Si}-\mathrm{O} 2$ & 112.42 & 112.59 & 2.0972 \\
\hline $\mathrm{O} 1-\mathrm{Si}-\mathrm{O} 3$ & 111.04 & 111.83 & 2.0972 \\
\hline $\mathrm{O} 1-\mathrm{Si}-\mathrm{O} 4$ & 111.06 & 110.25 & 2.0972 \\
\hline $\mathrm{O} 2-\mathrm{Si}-\mathrm{O} 3$ & 109.11 & 110.36 & 2.0972 \\
\hline $\mathrm{O} 2-\mathrm{Si}-\mathrm{O} 4$ & 106.95 & 105.77 & 2.0972 \\
\hline O3-Si-O4 & 105.97 & 105.63 & 2.0972 \\
\hline \multicolumn{4}{|c|}{${ }^{a}$ Observed values. ${ }^{3}$} \\
\hline
\end{tabular}

(c) Three body parameters 
Table 2 Calculated and experimental ${ }^{3}$ structural parameters for $\mathrm{La}_{8} \mathrm{Sr}_{2} \mathrm{Si}_{6} \mathrm{O}_{26}$ and $\mathrm{La}_{9.33} \mathrm{Si}_{6} \mathrm{O}_{26}$

(a) Lattice constants

\begin{tabular}{|c|c|c|c|c|}
\hline \multirow[b]{2}{*}{ Composition } & \multicolumn{2}{|c|}{ Experimental } & \multicolumn{2}{|c|}{ Calculated } \\
\hline & $a / b / \AA$ & $c / \AA ̊$ & $a / b / \AA$ & $c / \AA ̊$ \\
\hline $\mathrm{La}_{8} \mathrm{Sr}_{2} \mathrm{Si}_{6} \mathrm{O}_{26}$ & 9.7083 & 7.2377 & 9.8053 & 7.1558 \\
\hline $\mathrm{La}_{9.33} \mathrm{Si}_{6} \mathrm{O}_{26}$ & 9.7248 & 7.1895 & 9.7607 & 7.1198 \\
\hline
\end{tabular}

(b) Interatomic distances

\begin{tabular}{|c|c|c|c|c|}
\hline \multirow[b]{2}{*}{ Bond } & \multicolumn{2}{|c|}{$\mathrm{La}_{8} \mathrm{Sr}_{2} \mathrm{Si}_{6} \mathrm{O}_{26}$} & \multicolumn{2}{|c|}{$\mathrm{La}_{9.33} \mathrm{Si}_{6} \mathrm{O}_{26}$} \\
\hline & Exp/Å & Calc/Å & Exp/Å & Calc/Å \\
\hline $\mathrm{Si}-\mathrm{O} 1$ & 1.6189 & 1.6197 & 1.6111 & 1.6203 \\
\hline $\mathrm{Si}-\mathrm{O} 2$ & 1.6335 & 1.6298 & 1.6320 & 1.6269 \\
\hline $\mathrm{Si}-\mathrm{O} 3$ & 1.6243 & 1.6309 & 1.6201 & 1.6301 \\
\hline $\mathrm{Si}-\mathrm{O} 4$ & 1.6299 & 1.6318 & 1.6291 & 1.6310 \\
\hline Lal-O1 (× 3) & 2.5104 & 2.4767 & 2.5817 & 2.4530 \\
\hline $\mathrm{La} 1-\mathrm{O} 2(\times 3)$ & 2.5696 & 2.6103 & 2.5178 & 2.5802 \\
\hline $\mathrm{La} 1-\mathrm{O} 3(\times 3)$ & 2.8930 & 2.9506 & 2.9226 & 2.9180 \\
\hline $\mathrm{La} 2-\mathrm{O} 1(\times 3)$ & 2.4905 & 2.4789 & 2.4355 & 2.4554 \\
\hline $\mathrm{La} 2-\mathrm{O} 2(\times 3)$ & 2.5255 & 2.6097 & 2.5653 & 2.5807 \\
\hline $\mathrm{La} 2-\mathrm{O} 4(\times 3)$ & 2.8758 & 2.9410 & 2.8398 & 2.9081 \\
\hline La3-O1 & 2.7250 & 2.7516 & 2.7242 & 2.7691 \\
\hline $\mathrm{La} 3-\mathrm{O} 2$ & 2.5086 & 2.4924 & 2.5052 & 2.4681 \\
\hline La3-O3 & 2.4597 & 2.4703 & 2.4828 & 2.4553 \\
\hline La3-O4 & 2.4903 & 2.4708 & 2.4392 & 2.4566 \\
\hline La3-O5 & 2.3100 & 2.3211 & 2.3142 & 2.3207 \\
\hline $\mathrm{O} 5-\mathrm{O} 5$ & 3.5175 & 3.5709 & 3.5229 & 3.5513 \\
\hline O5-O5 & 3.7202 & 3.5849 & 3.6666 & 3.5691 \\
\hline
\end{tabular}

\subsection{Intrinsic atomic defects}

A series of calculations were carried out in which the energies of isolated point defects (vacancies and interstitials) were obtained. Our calculated vacancy energies (Table 3a) clearly indicate that for both compositions an oxygen vacancy at the channel $\mathrm{O} 5$ position is more favourable than at the silicate tetrahedra sites. This is in good accord with previous experimental speculation that oxygen conduction occurs along the O5 channels in the structure. We similarly find that the most favourable La vacancy is at the La1/La2 positions. Again this agrees well with experimental observation that in cation-deficient materials, such as $\mathrm{La}_{9.33} \mathrm{Si}_{6} \mathrm{O}_{26}$, these sites assume partial occupancy. Within the more covalent $\mathrm{SiO}_{4}$ units, the Si vacancy defects were found to be unstable to energy minimisation.

Combining the energies for these point defects, we then derived energies of formation for Frenkel and Schottky-type disorders. For example, in Kroger-Vink notation these take the general form:

$$
\mathrm{O}_{\mathrm{o}}^{\mathrm{x}} \rightarrow \mathrm{V}_{\mathrm{o}}^{\cdot}+\mathrm{O}_{\mathrm{i}}^{\prime \prime}
$$

for an oxygen Frenkel defect, and

$$
2 \mathrm{La}_{\mathrm{La}}^{\mathrm{x}}+3 \mathrm{O}_{\mathrm{o}}^{\mathrm{x}} \rightarrow 2 \mathrm{~V}_{\mathrm{La}}^{\prime \prime \prime}+3 \mathrm{~V}_{\mathrm{o}}^{*}+\mathrm{La}_{2} \mathrm{O}_{3}
$$

for a lanthanum Schottky-type disorder.

Using our vacancy energies to derive Schottky-type energies in the systems (Table 4), we find that such disorder is not highly favourable. As expected, both $\mathrm{La}$ and $\mathrm{Sr}$ Frenkel defects are predicted to be energetically unfavourable. With respect to oxygen interstitial defects, several possible positions were considered (Table 3b). We focused initially on an O6 site located midway between the channel $\mathrm{O} 5$ positions. Calculating the energetics of oxygen Frenkel disorder we found that our model gave similar results for the two compositions; the magnitude of the formation energies suggests that such
Table 3 Calculated energies for isolated defects

(a) Ionic vacancies

\begin{tabular}{llc}
\hline & \multicolumn{2}{l}{ Defect energy/eV } \\
\cline { 2 - 3 } Vacancy & $\mathrm{La}_{8} \mathrm{Sr}_{2} \mathrm{Si}_{6} \mathrm{O}_{26}$ & $\mathrm{La}_{9.33} \mathrm{Si}_{6} \mathrm{O}_{26}$ \\
\hline O1 & 23.10 & 23.05 \\
O2 & 20.21 & 23.19 \\
O3 & 20.56 & 20.71 \\
O4 & 20.59 & 20.73 \\
O5 & 19.14 & 19.28 \\
Si & $\mathrm{NC}^{a}$ & $\mathrm{NC}^{a}$ \\
La1 & 44.37 & 44.16 \\
La2 & 44.44 & 44.23 \\
La3 & 47.84 & 47.76 \\
Sr1 & 21.00 & - \\
Sr2 & 21.04 & -
\end{tabular}

\begin{tabular}{|c|c|c|c|c|}
\hline \multirow[b]{2}{*}{ Interstitial } & \multicolumn{2}{|l|}{$\mathrm{La}_{8} \mathrm{Sr}_{2} \mathrm{Si}_{6} \mathrm{O}_{26}$} & \multicolumn{2}{|l|}{$\mathrm{La}_{9.33} \mathrm{Si}_{6} \mathrm{O}_{26}$} \\
\hline & Position (frac) & $\begin{array}{l}\text { Energy/ } \\
\text { eV }\end{array}$ & Position (frac) & $\begin{array}{l}\text { Energy/ } \\
\mathrm{eV}\end{array}$ \\
\hline O6 & $\begin{array}{l}0.0000,0.0000 \\
0.5000\end{array}$ & -12.09 & $\begin{array}{l}0.0000,0.0000 \\
0.5000\end{array}$ & -12.36 \\
\hline O7 & $\begin{array}{l}0.0125,0.2317 \\
0.8673\end{array}$ & -12.72 & $\begin{array}{c}0.0135,0.2333 \\
0.8763\end{array}$ & -13.00 \\
\hline $\mathrm{O} 7$ & $\begin{array}{l}0.0128,0.2315 \\
0.6159\end{array}$ & -12.72 & $\begin{array}{l}0.0130,0.2326 \\
\quad 0.6246\end{array}$ & -12.99 \\
\hline
\end{tabular}

(b) Oxygen interstitials

${ }^{a}$ Non convergence.

disorder is again possible, but not highly favourable. We note that this does not fully explain the structural disorder proposed for $\mathrm{La}_{9.33} \mathrm{Si}_{6} \mathrm{O}_{26}$, which suggests that $\mathrm{O} 6$ occupancy in this material may not arise from Frenkel disorder of this type.

In order to probe for the most favourable oxygen interstitial site we performed a series of further calculations in which oxygen ions were placed in various sites around the channel and their position allowed to relax. Using this approach, two low energy interstitial positions were found for each composition, which lie at the periphery of the $\mathrm{O} 5$ channel (Table $3 \mathrm{~b}$ ) and were found to be about $0.6 \mathrm{eV}$ more stable than the $\mathrm{O} 6$ position. It can be seen that for both compositions they show identical formation energies, since the sites are effectively equivalent: if the structure is described in terms of the $P 6_{3} / m$ space group, the positions change from being separate six-fold sites to being equivalent as a single twelve-fold site. We have thus treated the positions as identical with the label "O7".

Further analysis of the $\mathrm{O} 7$ interstitial calculation indicates that the ion lies almost entirely out of the large open channel (Fig. 2). This defect causes considerable distortion of the nearby $\mathrm{SiO}_{4}$ tetrahedral unit with the largest displacement for the adjacent $\mathrm{O} 3$ oxygen of $1.3 \AA$. This result suggests the need for further structural work to examine such oxygen defect sites, although we recognise that diffraction analysis of such local distortions will be extremely difficult. The high thermal

Table 4 Energies of disorder for $\mathrm{La}_{8} \mathrm{Sr}_{2} \mathrm{Si}_{6} \mathrm{O}_{26}$ and $\mathrm{La}_{9.33} \mathrm{Si}_{6} \mathrm{O}_{26}$

\begin{tabular}{lcc}
\hline & \multicolumn{2}{c}{ Defect energy/eV defect } \\
\cline { 2 - 3 } Disorder & $\mathrm{La}_{8} \mathrm{Sr}_{2} \mathrm{Si}_{6} \mathrm{O}_{26}$ & $\mathrm{La}_{9.33} \mathrm{Si}_{6} \mathrm{O}_{26}$ \\
\hline La1/O5 Schottky-type & 3.25 & 3.25 \\
Sr1/O5 Schottky-type & 3.35 & - \\
O5 to "O6" Frenkel & 3.52 & 3.45 \\
O5 to "O7" Frenkel & 3.20 & 3.13 \\
La Frenkel & 12.40 & 12.65 \\
Sr Frenkel & 9.21 & -
\end{tabular}




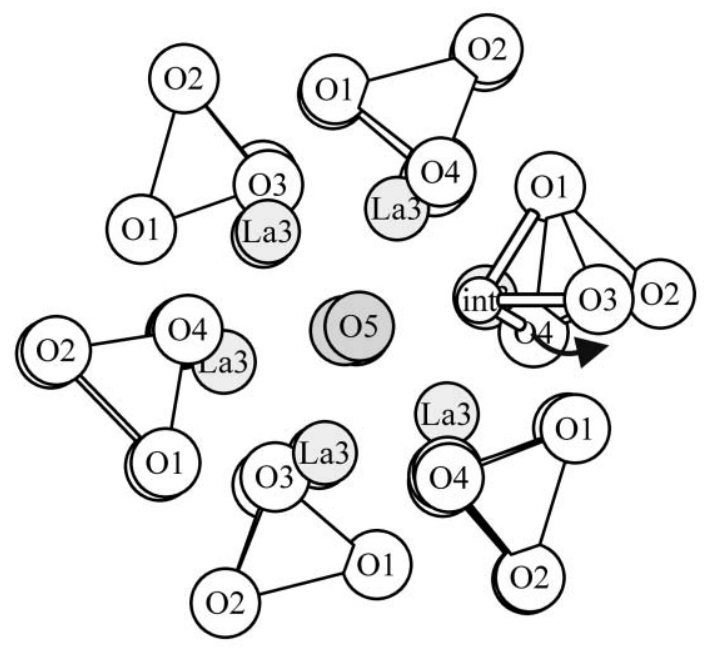

Fig. 2 The "O7" oxygen interstitial defect and surrounding lattice relaxation. Ion displacements of adjacent tetrahedron: O1 (0.1 $\AA), \mathrm{O} 2$ (0.4 ̊̊), O3 (1.3 $), \mathrm{O} 4(0.2 \AA), \mathrm{Si}(0.2 \AA)$.

displacement parameters for the silicate oxygens and distortion of the tetrahedra found from diffraction work ${ }^{3,4}$ may, however, give some support to the presence of such sites.

\subsection{Oxygen ion migration}

Although conductivity studies provide accurate activation energies, it is not always possible to associate the observed values with a particular diffusion mechanism. Atomistic calculations have been used to investigate these problems by an extensive search of the potential energy surface for oxygen migration. The energy profiles were mapped out by calculating the defect energy of the migrating ion along the diffusion path, and allowing relaxation of the lattice at each position. In this way the saddle-point configuration may be identified, from which the energy barrier to migration is derived. Such an approach has been used to investigate oxygen ion transport in $\mathrm{LaMO}_{3}$ perovskites. $^{12-14}$

In this work, our methodology was to calculate a series of defect energies at fixed positions along the $c$-axis channel between vacancy and interstitial oxygen positions, whilst allowing the anion to relax in the $a / b$ plane. At the calculated saddle-point configuration, additional calculations were performed at fixed positions into the channel in order to produce a contour map of the potential energy surface in the $a / b$ plane. The calculated activation energies for oxygen ion migration have been correlated with the available experimental values and are reported in Table 5 .

Two main points emerge from these results. First, the correlation between simulation and experiment strongly suggests that the lower conductivity and higher activation energy $\left(>1.1 \mathrm{eV}\right.$ ) in $\mathrm{La}_{8} \mathrm{Sr}_{2} \mathrm{Si}_{6} \mathrm{O}_{26}$ is via a vacancy mechanism with a negligible population of oxygen interstitial ions in this phase. The lowest energy route for vacancy migration is predicted to be a linear path, with saddle-points mid-way between the $\mathrm{O} 5$ positions (Fig. 3). We note that vacancy migration is found in well-known oxygen ion conductors of the

Table 5 Calculated and experimental activation energies for oxygen ion migration

\begin{tabular}{lcl}
\hline & \multicolumn{2}{c}{ Activation energy/eV } \\
\cline { 2 - 3 } Composition & Calculated & Experimental ${ }^{2,5}$ \\
\hline $\mathrm{La}_{8} \mathrm{Sr}_{2} \mathrm{Si}_{6} \mathrm{O}_{26}$ & $1.26^{a}$ & 1.14 \\
$\mathrm{La}_{9.33} \mathrm{Si}_{6} \mathrm{O}_{26}$ & $0.56^{b}$ & $0.65 ; 0.74$ \\
${ }^{a} \mathrm{Vacancy}^{b}$ mechanism. & ${ }^{b}$ Interstitial mechanism. & \\
\hline
\end{tabular}

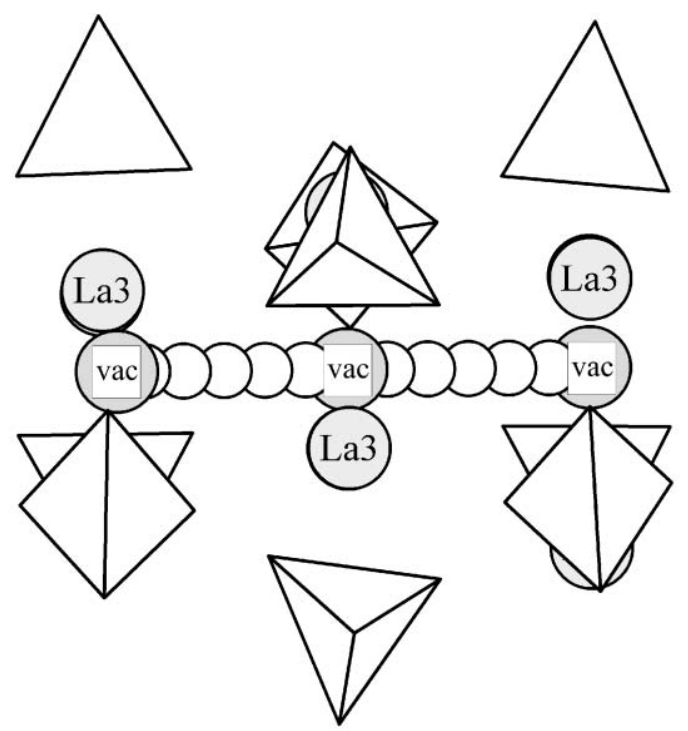

Fig. 3 O5 oxygen vacancy migration along the O5 oxide channel.

fluorite-type (e.g. $\mathrm{Y} / \mathrm{ZrO}_{2}$ ) and perovskite-type (e.g. doped $\mathrm{LaGaO}_{3}$ ).

We also find that the migration may have a two-stage mechanism (Fig. 4), arising from the fact that $\mathrm{O} 5$ positions are not equidistant, although the calculated energies are almost identical. The contour map of energies taken at the first saddlepoint shows that the energies become increasingly unfavourable at large distances from the channel centre (as an example the contour map for $\mathrm{La}_{8} \mathrm{Sr}_{2} \mathrm{Si}_{6} \mathrm{O}_{26}$ is shown in Fig. 5). Interestingly, the contour map also shows that for positions up to $0.5 \AA$ away from the channel centre there is an almost flat energy surface. This gives a large area in the $a / b$ plane of very similar energy around the centre of the channel indicating that there is a wide "tunnel" along which O5 vacancy migration can occur.

Second, $\mathrm{O}^{2-}$ interstitial migration through the channels is predicted for $\mathrm{La}_{9.33} \mathrm{Si}_{6} \mathrm{O}_{26}$ with significantly lower activation energy (Table 5). The bulk activation energy in polycrystalline $\mathrm{La}_{9.33} \mathrm{Si}_{6} \mathrm{O}_{26}$ has been reported as $0.65 \mathrm{eV}^{8}$ and $0.74 \mathrm{eV} .^{3}$ It is worth noting that Nakayama et al. ${ }^{26}$ have studied singlecrystals of the neodymium analogue, $\mathrm{Nd}_{9.33} \mathrm{Si}_{6} \mathrm{O}_{26}$, and find conductivity parallel to the $c$-axis has an activation energy of $0.62 \mathrm{eV}$, which accords well with our calculated value of $0.56 \mathrm{eV}$ for oxygen interstitial migration through the $c$-axis channel of $\mathrm{La}_{9.33} \mathrm{Si}_{6} \mathrm{O}_{26}$.

The lowest energy migration path for the $\mathrm{O}^{2-}$ interstitial is predicted to be a non-linear ("sinusoidal-like") mechanism

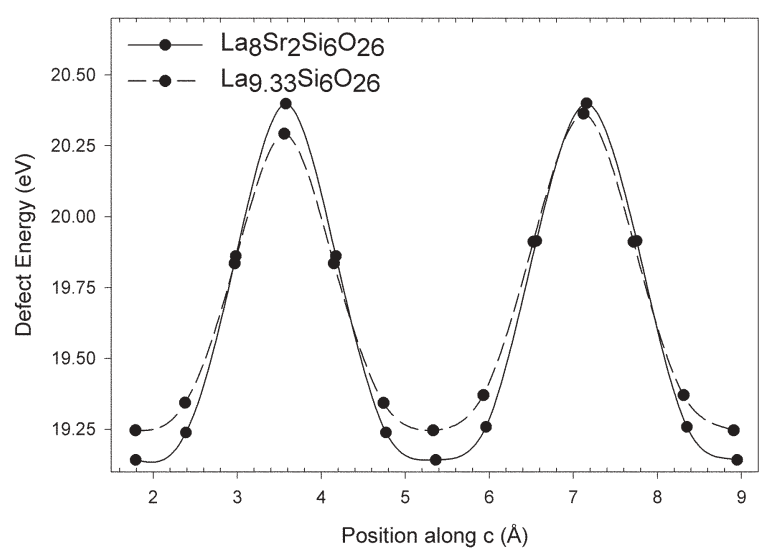

Fig. 4 Energy profile of vacancy migration in $\mathrm{La}_{8} \mathrm{Sr}_{2} \mathrm{Si}_{6} \mathrm{O}_{26}$ and $\mathrm{La}_{9.33} \mathrm{Si}_{6} \mathrm{O}_{26}$ indicating the two stages between differently spaced $\mathrm{O} 5$ positions. 


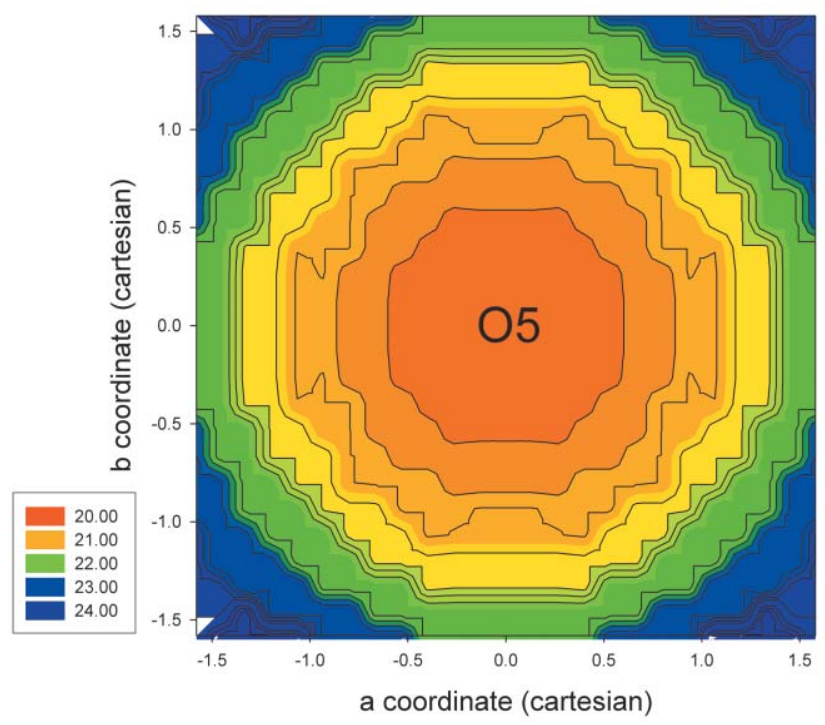

Fig. 5 Contour plot (in the $a / b$ plane) of the energy surface at the saddle-point for $\mathrm{O} 5$ oxygen vacancy migration in $\mathrm{La}_{8} \mathrm{Sr}_{2} \mathrm{Si}_{6} \mathrm{O}_{26}$.

(illustrated in Fig. 6) as found in our preliminary communication. ${ }^{27}$ A potential map of the $a / b$ plane was also generated (Fig. 7) and indicates that the saddle-point is away from the channel centre. We note that at the location on the conduction route where the interstitial anion has to pass an $\mathrm{O} 5$ oxygen, the lowest energy pathway lies much closer to the channel periphery than to the $\mathrm{O} 5$ position. This pathway involves migration across the face of a silicate tetrahedral unit, coupled with considerable local relaxation. From our analysis of the saddle-point configuration we find displacements of $0.2 \AA$ and $0.6-1.0 \AA$ for the $\mathrm{Si}$ and the nearest oxygen ions $(\mathrm{O} 1, \mathrm{O} 3, \mathrm{O} 4)$ respectively; these displacements are generally away from the channel and towards the cation-deficient La1/La2 positions, which may indicate the influence of the $\mathrm{La}$ vacancies in $\mathrm{La}_{9.33} \mathrm{Si}_{6} \mathrm{O}_{26}$ as proposed previously. ${ }^{3,6}$ This suggests that the local cooperative relaxation of the $\left[\mathrm{SiO}_{4}\right]$ tetrahedra is an important factor for facile oxygen ion conduction.

\section{Conclusions}

Computer modelling techniques have been used to examine the mechanistic features of oxygen ion transport in the $\mathrm{La}_{8} \mathrm{Sr}_{2}-$ $\mathrm{Si}_{6} \mathrm{O}_{26}$ and $\mathrm{La}_{9.33} \mathrm{Si}_{6} \mathrm{O}_{26}$ apatite phases at the atomic level,

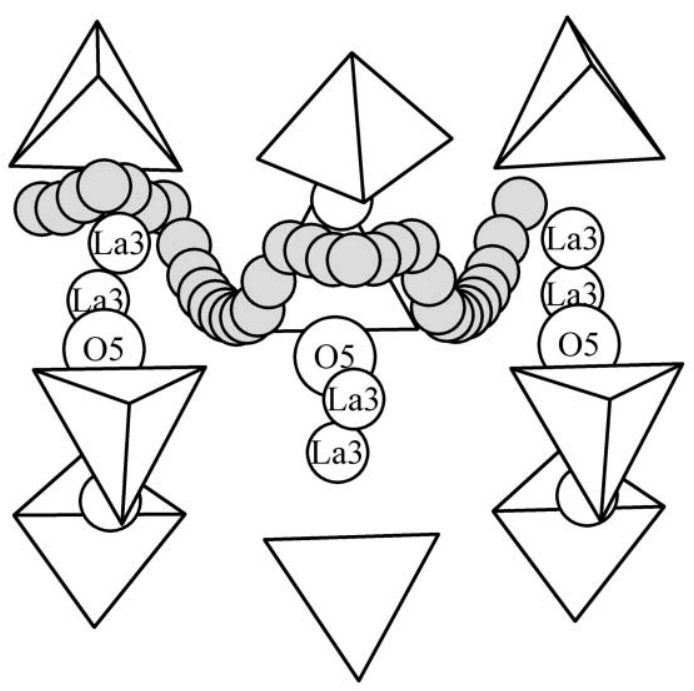

Fig. 6 Interstitial oxygen migration viewed perpendicular to the O5 channel, showing a non-linear (sinusoidal-like) pathway.

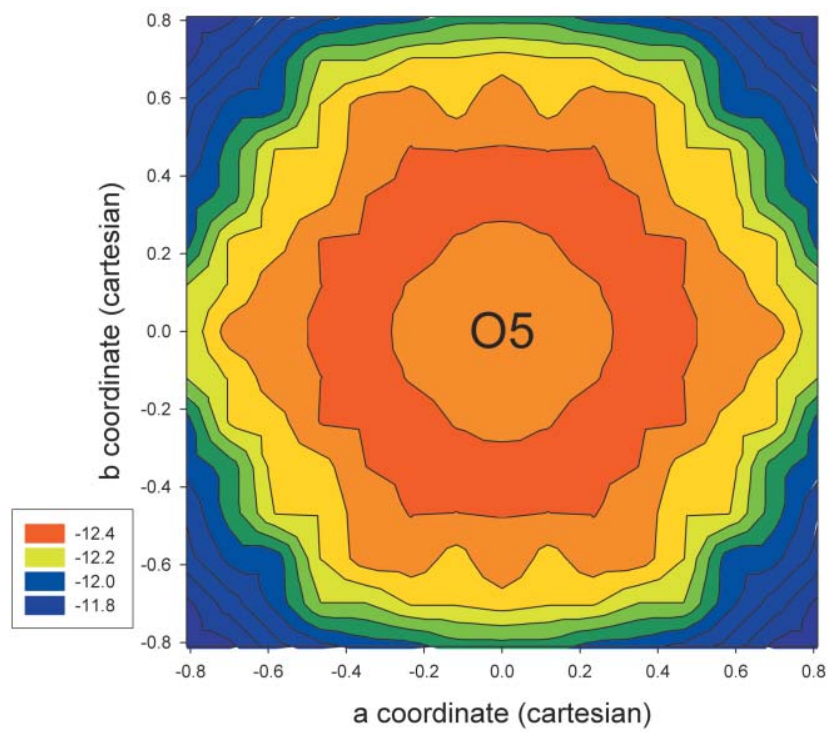

Fig. 7 Contour plot (in the $a / b$ plane) of the energy surface at the saddlepoint for interstitial migration within the $\mathrm{O} 5$ channel of $\mathrm{La}_{9.33} \mathrm{Si}_{6} \mathrm{O}_{26}$.

which are relevant to their potential use in electrochemical applications. The following main points emerge from this study.

(1) The potential model reproduces the observed hexagonal structures of both $\mathrm{La}_{8} \mathrm{Sr}_{2} \mathrm{Si}_{6} \mathrm{O}_{26}$ and $\mathrm{La}_{9.33} \mathrm{Si}_{6} \mathrm{O}_{26}$, which exhibit significant structural complexity. These phases may be viewed as "hybrid" structures comprised of covalent-like $\left[\mathrm{SiO}_{4}\right]$ tetrahedral units and ionic-like $\mathrm{La} / \mathrm{O}$ channels.

(2) The lowest energy interstitial site (O7) is predicted to lie at the periphery of the La3/O5 channel. The point defect energies show that the preferred cation and oxygen vacancy sites are La1/2 and 05 respectively, in accord with observation.

(3) The simulations indicate that oxygen ion migration in $\mathrm{La}_{8} \mathrm{Sr}_{2} \mathrm{Si}_{6} \mathrm{O}_{26}$ is via a vacancy mechanism with a direct linear path between $\mathrm{O} 5$ sites. The calculated activation energy of $1.26 \mathrm{eV}$ correlates well with the experimental value of $1.14 \mathrm{eV}$, and suggests a negligible population of oxygen interstitial ions in this phase.

(4) Interstitial oxygen migration is predicted for $\mathrm{La}_{9}{ }_{33} \mathrm{Si}_{6} \mathrm{O}_{26}$ via a non-linear (sinusoidal-like) pathway along the $c$-axis La3/O5 oxide channel. The calculated activation energy of $0.56 \mathrm{eV}$ is lower than that for vacancy migration, but is compatible with the available experimental value of $0.74 \mathrm{eV}$ for this phase (and of $0.62 \mathrm{eV}$ for $c$-axis conductivity in $\mathrm{Nd}_{9.33} \mathrm{Si}_{6} \mathrm{O}_{26}$ single crystals). The simulations demonstrate the importance of local cooperative relaxation of $\left[\mathrm{SiO}_{4}\right]$ tetrahedra (towards the vacant La sites) to assist in the facile conduction of oxygen interstitial ions.

In general, the atomistic modelling study confirms that the high ionic conductivity in the silicate-based apatites with oxygen excess or cation vacancies is mediated by oxygen interstitial migration (with low activation energies of about $0.6-0.7 \mathrm{eV}$ ). Future work on these apatite phases will encompass defect calculations on dopant incorporation and molecular dynamics (MD) simulations of oxygen diffusion.

\section{Acknowledgements}

We would like to acknowledge the EPSRC for financial support, J. D. Gale for the use of the GULP code and the JREI-funded Compaq computing facilities at RAL.

\section{References}

1 S. Nakayama, T. Kagayama, H. Aono and Y. Sadoaka, J. Mater. Chem., 1995, 5, 1801. 
2 S. Nakayama and M. Sakamoto, J. Eur. Ceram. Soc., 1998, 18, 1413

3 J. E. H. Sansom, D. Richings and P. R. Slater, Solid State Ionics, 2001, 139, 205.

4 P. R. Slater and J. E. H. Sansom, Solid State Phenomena, 2003, 9091, 195.

5 J. E. H. Sansom and P. R. Slater, Proc. 5th Euro. SOFC Forum, 2002.

6 E. J. Abram, D. C. Sinclair and A. R. West, J. Mater. Chem., 2001, 11, 1978.

7 H. Arikawa, N. Nishiguchi, T. Ishihara and Y. Takita, Solid State Ionics, 2000, 136-137, 31.

8 S. Tao and J. T. S. Irvine, Mater. Res. Bull., 2001, 36, 1245.

9 J. E. H. Sansom, L. Hildebrandt and P. R. Slater, Ionics, 2002, 8, 155.

10 J. E. H. Sansom and P. R. Slater, Solid State Phenomena, 2003, 9091, 189.

11 J. MacFarlane, S. Barth, M. Swaffer, J. E. H. Sansom and P. R. Slater, Ionics, 2002, 8, 149.

12 M. Cherry, M. S. Islam and C. R. A. Catlow, J. Solid State Chem., 1995, 118, 125.

13 M. S. Islam, J. Mater. Chem., 2000, 10, 1027.

14 M. S. Islam, Solid State Ionics, 2002, 154-155, 75.

15 N. H. de Leeuw, Chem. Mater., 2002, 14, 435.
16 J. D. Gale, J. Chem. Soc., Faraday Trans, 1997, 93, 629.

17 C. R. A. Catlow, in Solid State Chemistry - Techniques, ed. A. K. Cheetham and P. Day, Clarendon Press, Oxford, 1987.

18 (a) C. R. A. Catlow, Computer Modelling in Inorganic Crystallography, Academic Press, San Diego, 1997; (b) F. M. Higgins, N. H. de Leeuw and S. C. Parker, J. Mater. Chem., 2002, 12, 124; (c) D. W. Lewis, C. R. A. Catlow and J. M. Thomas, Faraday Discuss., 1997, 106, 451.

19 A. Jones, D. Palmer, M. S. Islam and M. Mortimer, Phys. Chem. Minerals, 2001, 28, 28.

20 B. Dick and A. Overhauser, Phys. Rev., 1958, 112, 90.

21 R. A. Jackson and C. R. A. Catlow, Mol. Sim., 1998, 1, 207.

22 J. D. Gale and N. J. Henson, J. Chem. Soc., Faraday Trans., 1994, 90, 3175 .

23 G. V. Lewis and C. R. A. Catlow, J. Phys. C: Solid State Phys., 1985, 18, 1149.

24 M. S. Khan, M. S. Islam and D. R. Bates, J. Mater. Chem., 1998, 8, 2299.

25 D. J. Ilett and M. S. Islam, J. Chem. Soc., Faraday Trans., 1993, 89, 3833 .

26 S. Nakayama, M. Sakamoto, M. Highchi and K. Kodaira, J. Mater. Sci. Lett., 2000, 19, 91.

27 M. S. Islam, J. R. Tolchard and P. R. Slater, Chem. Commun., 2003, DOI: 10.1039/b301179h. 